\title{
Diagnosis and Management of Uterine Fibromyomas in the Obstetric Gynecology Department of the Regional Hospital of Labe. Guinea
}

\author{
Boubacar Siddi Diallo $^{1 *}$, Boubacar Alpha Diallo ${ }^{1}$, Mamadou Samba Camara ${ }^{1}$, Abdourahamane Diallo ${ }^{2}$, Daniel Leno ${ }^{1}$, Ibrahima Sory Balde ${ }^{2}$, \\ Telly $\mathrm{Sy}^{2}$, Yolande Hyjazi ${ }^{1}$, Namory Keita ${ }^{1}$ \\ ${ }^{1}$ University Department of Gynecology Obstetrics, Donka national Hospital, Conakry Guinea \\ ${ }^{2}$ University Department of Gynecology Obstetrics, Ignace Deen national Hospital, Conakry Guinea
}

*Correspondence: Docteur Diallo Boubacar Siddi, Gynecologist- Obstetrician. Lecturer at Conakry University Teaching Hospital.

Received date: August 10, 2021; Accepted date: August 27, 2020; Published date: September 06,2021

Citation: Boubacar S. Diallo, Boubacar A. Diallo, Mamadou S. Camara Diallo A., Leno D., Ibrahima S. Balde, Telly Sy, Hyjazi Y., Keita N., (2021) Impact of an Educational Program on Sexual Issues among Cervical Cancer Survivors' Women in Northern Upper Egypt. J. Obstetrics Gynecology and Reproductive Sciences 5(6); DOI: 10.31579/2578-8965/061

Copyright: () 2021, Boubacar Siddi Diallo, This is an open access article distributed under the Creative Commons Attribution License, which permits unrestricted use, distribution, and reproduction in any medium, provided the original work is properly cited.

\begin{abstract}
Objectives: To calculate the frequency of uterine fibromyomas, to describe the epidemiological profile, to describe the management and to establish the prognosis of women with uterine fibromyomas in the gynaecology-obstetrics department of the Regional Hospital of Labé.

Methodology: This was a retrospective descriptive study lasting three (3) years from 1 January 2017 to 31 December 2019. All patients admitted and operated on in the department for uterine fibromyomas during the study period were included. Patients who were not operated for uterine fibromyomas in the department and incomplete records were not included. Our data were collected and analysed using Epi-Info software version 7.2.2.6. Word, Excel and Power point software from Pack office 2016 were used for data entry and presentation. The study involved a continuous series of 115 anaemic pregnant women. We proceeded with an exhaustive recruitment of pregnant women according to the criteria defined above.

Results: The frequency of uterine fibromyomas among gynaecological pathologies was $44.75 \%$. The epidemiological profile was that of a $30-39 \%$ (40.87\%), housewife (53.91\%) and nulliparous (40\%) woman. Pelvic pain was the dominant reason for consultation $(75.65 \%)$ and $46.08 \%$ of patients had no particular history. Intramural or interstitial uterine fibromyomas were the most common (49.57\%) and ultrasound was performed in all patients. The surgical indications were dominated by large polymyomatous uterus $37.39 \%$, followed by haemorrhagic fibroid $26.09 \%$. Myomectomy was performed in $75.65 \%$ of cases, exclusively via the abdominal route $(100 \%)$, while hysterectomy was performed via the abdominal route in $17.39 \%$ of cases and vaginal route in $6.96 \%$. The postoperative course was simple in $75.65 \%$ of cases and complicated in $24.35 \%$. Complications were dominated by anaemia (13.04). The average length of stay was 6.05 days with extremes of 3 and 13 days.
\end{abstract}

Conclusion: The frequency of the uterine fibromyomas is raised in the region of Labé and the hold in charge is often surgical

Key words: diagnosis ; fibromyomas ; labé

\section{Introduction}

Uterine fibromyomas (UF) are benign tumours that correspond to a degenerative proliferation of the connective tissue and smooth muscle of the uterus that condense into a pseudo-capsule [1].They represent a major problem for women of reproductive age, as they are often responsible for infertility, after eliminating all other causes [2].UF is most often asymptomatic. However, the location and size of the myomatous nucleus (es) may determine the occurrence of various clinical manifestations such as menometrorrhagia, pelvic pain, constipation, dysuria and infertility warranting treatment [3]. They may be isolated or multiple and may be interstitial, subserosal or submucosal, sessile or pedunculated. They are usually corporal and rarely cervical. They can range in size from a grain 
of rice to a full term uterus [4]. Currently, the diagnosis of FU is made by ultrasound and diagnostic hysteroscopy. Magnetic resonance imaging (MRI) is used as a second line of treatment and allows precise pretreatment mapping from 5 fibroids or more or in the case of associated uterine pathology such as adenomyosis [5]. FU can thus cause serious obstetric complications (spontaneous miscarriage, premature delivery, prævia obstacles, postpartum haemorrhage, dynamic dystocia, and endometritis) and non-obstetric complications (acute torsion; bladder, urethral, rectal and intestinal compressions; anaemia; aseptic necrobiosis) [2].

In Canada, FU is common (with an incidence of $70 \%$ at age 50). Between $20 \%$ and $50 \%$ of these fibroids are symptomatic and have considerable social and economic impact [6].In France, FU is a common condition and is the leading cause of hysterectomy [7]. In Africa, uterine fibroid disease is very common and represents a real public health problem. Indeed, myomas develop in 20 to $25 \%$ of women over 30 years of age and can affect up to $60 \%$ of black women from the age of 35 [8]. [9] In 2020 reported in her study $25.78 \%$ of the impact and management of FU in Mali, Coulibaly A. et al. [In Guinea, Diallo M.H et al. In Guinea, Diallo M.H et al [11] in 2020 reported $51.92 \%$ of FU operated on at the Ratoma CMC. Baldé I.S et al. [12] in 2014 reported that the most frequently encountered operative indication for hysterectomy at Conakry University Hospital was FU (39.6\%).

The objectives of this study were to calculate the frequency of uterine fibromyomas, to describe the epidemiological profile, to describe the management and to establish the prognosis of women with uterine fibromyomas in the gynaecology-obstetrics department of the regional hospital of Labé.

\section{Methodology}

This was a retrospective descriptive study lasting three (3) years from 1 January 2017 to 31 December 2019. All the records of patients admitted and operated in the department for uterine fibromyomas during the study period were included. All the cases recorded without operation for uterine fibromyomas in the department and incomplete records were not included. Our data were collected and analysed using Epi-Info software version 7.2.2.6. Word, Excel and Power point software from 2016 Pack office were used for data entry and presentation. The study involved a continuous series of 115 anaemic pregnant women. We proceeded to an exhaustive recruitment of pregnant women according to the criteria defined above. The variables studied were: epidemiological (frequency, age, socio-professional strata and parity), clinical and paraclinical (reasons for consultation, history, location, associated pathologies and ultrasound), therapeutic (operative indications, type of approach and operative procedure), prognostic (duration of hospitalisation and postoperative follow-up).

\section{Results}

1-Frequency: out of 257 gynaecological conditions, we recorded 115 cases of operated uterine fibromyomas, i.e. a frequency of $44.75 \%$.

\section{2-Epidemiological profile}

-Age: the 30-39 age group was the most concerned (40.87\%). The average age was 37.74 years with extremes of 20 and 65 years.

- Occupation: housewives were the most affected $53.91 \%$, followed by professional women $25.22 \%$.

-Parity: we recorded $40 \%$ nulliparous, $23.48 \%$ primiparous, $13.91 \%$ pauciparous, $13.04 \%$ multiparous and $9.56 \%$ grand multiparous.

\section{3-Clinical}

-Reasons for consultation: pelvic pain was the dominant reason for consultation with $75.65 \%$, followed by genital haemorrhage $55.65 \%$ against $12.17 \%$ of urinary and digestive disorders.

-Previous history: $15.65 \%$ of the women operated on had already undergone a myomectomy and $17.39 \%$ of them complained of infertility.

-Location of myomas: Intramural or interstitial uterine fibromyomas were the most common, $49.57 \%$, followed by submucosal uterine fibromyomas (20.87\%).

-Associated pathologies: the association with ovarian cyst was the most frequent $15.65 \%$ followed by hydrosalpinx $8.70 \%$, cervical cancer $4.35 \%$ and prolapse $0.87 \%$.

-Ultrasound: it was performed in all patients (100\%).

\section{4-Therapeutics}

-Operative indications: were dominated by polymyomatous large uterus $37.39 \%$, followed by bleeding fibroid $26.09 \%$. The combination of uterine fibromyomas and infertility represented $17.39 \%$.

-Type of approach and surgical procedure: myomectomy was the dominant procedure, i.e. $75.65 \%$, exclusively via the abdominal route $(100 \%)$, while hysterectomy was performed in $24.35 \%$ : abdominal route (laparotomy) $17.39 \%$ and vaginal route $6.96 \%$.

\section{5-Pronosis}

-Duration of hospitalization: we found that $48.70 \%$ of patients were hospitalized between 3 and 5 days. The average length of stay was 6.05 days with extremes of 3 and 13 days.

Postoperative follow-up: The postoperative follow-up was simple in $75.65 \%$ and complicated in $24.35 \%$. Complications were dominated by anaemia in $13.04 \%$, which myomectomy was haemorrhagic, requiring a blood transfusion in $6.09 \%$. We also recorded $5.22 \%$ of parietal suppurationHowever, there were no cases of postoperative death.

\section{Discussion}

1-Frequency: out of 257 gynaecological conditions, we recorded 115 cases of operated uterine fibromyomas, i.e. a frequency of $44.75 \%$. This result is comparable to that found by Baldé I.S et al. [13] in 2015 at Conakry University Hospital, i.e. $42.4 \%$, but lower than the $51.92 \%$ reported by Diallo M.H et al. [11] in 2020 at the Ratoma CMC. This high frequency could be explained by the fact that our study took place in a structure that is at the top of the health pyramid in the Labé region.

\section{2-Epidemiological profile}

-Age: the 30-39 age group was the most concerned (40.87\%). The average age was 37.74 years with extremes of 20 and 65 years. Our results corroborate those of Diallo M.H. et al. [11] at the Ratoma CMC in 2020 reporting an average age of 37 years with a frequency of occurrence between 30-39 years (49.63\%). [9] In 2020 in Morocco ___ reported an average age of 42.7 years with a predominance between $40-50$ years. This frequency observed in our series could be explained by the fact that FU is a pathology of the woman in full genital activity and that because of a relative hyperoestrogenism. However, a rate of $19.13 \%$ was recorded for the 20-29 age group, which reinforces the idea that in black women, uterine fibromyomas are increasingly found in young women. [13].

- Profession: housewives were the most affected $53.91 \%$, followed by women in the careers $25.22 \%$. This result is close to the $57.14 \%$ of housewives reported by Onikoyamou F. This result is close to the $57.14 \%$ of housewives reported by Onikoyamou F. [14] at Kamsar hospital. 
This predominance could be explained by the fact that housewives constitute the highest percentage of the female population in Guinea in general, but also in the Labé region.

- Parity: we recorded $40 \%$ nulliparous, $23.48 \%$ primiparous, $13.91 \%$ pauciparous, $13.04 \%$ multiparous and $9.56 \%$ large multiparous. We note that the increase in parity is inversely proportional to the frequency of appearance of uterine fibromyoma. The same observation was made by Diallo M.H. et al. [11] who found: $45.18 \%$ nulliparous, $24.44 \%$ primiparous, $15.60 \%$ pauciparous, $13.33 \%$ multiparous and $1.48 \%$ large multiparous. This observation is in line with the theory of Marshall L.M. and Parazzini F., who state that the reduction in the risk of fibromyomas is linked to parity and that this risk decreases with the number of births [15].

\section{3-Clinical}

-Reasons for consultation: pelvic pain was the dominant reason for consultation with $75.65 \%$, followed by genital haemorrhage $55.65 \%$ against $12.17 \%$ of urinary and digestive disorders. Magassouba D. [16] reported that $39 \%$ of patients consulted for genital haemorrhage and $27.5 \%$ for pelvic pain. The associated infertility assessment was a circumstance for the discovery of fibromyomas in $17.39 \%$ of patients.

- Antecedents: we recorded that $15.65 \%$ of the women operated on had already undergone a myomectomy and that $17.39 \%$ of them complained of infertility. This result is relatively higher than the $13.13 \%$ of myomectomies reported by Traoré D.V [2] at the regional hospital of N'Zérékoré. However, 46.08\% of the patients had no particular antecedents. In the medium term, the main complication after myomectomy is recurrence. [2]

- Location of myomas: intra mural or interstitial uterine fibromyomas were the most common, $49.57 \%$, followed by submucosal uterine fibromyomas (20.87\%).Our results are comparable to those found by Baldé I.S et al. Our results are comparable to those found by Baldé I.S et al [13], i.e. $48.8 \%$ of intra-mural uterine fibromyomas and $32.3 \%$ of submucosal uterine fibromyomas. Knowledge of the topography of uterine myomas is important in the choice of treatment.

- Associated pathologies: the association with ovarian cyst was the most common $15.65 \%$ followed by hydrosalpinx $8.70 \%$, cervical cancer $4.35 \%$ and prolapse $0.87 \%$. Baldé I.S et al. [13] report an association of $11 \%$ ovarian cyst and $2.32 \%$ hydrosalpinx. Fofana M.S. [17] found a $0.74 \%$ association with cervical cancer in his study at the Ratoma CMC.

- Ultrasound: it was performed in all patients (100\%). Our result is identical to that of Laghzaoui M. et al [18] in Morocco.

\section{4-Therapeutics}

-Operative indications: were dominated by polymyomatous large uterus $37.39 \%$, followed by haemorrhagic fibroid $26.09 \%$. The association of uterine fibromyomas and infertility represented $17.39 \%$.Our observation is shared by Diallo M.H. et al. Our observation is shared with Diallo M.H. et al [11] at the Ratoma CMC, who reported in their series that the indications for surgery were dominated by large polymyomatous uterus, i.e. $64.44 \%$, followed by haemorrhagic fibromyoma, i.e. $18.52 \%$, and infertility, which represented $17.04 \%$.

Therapeutic intervention must be motivated by the existence of a troublesome symptom and only clinical monitoring is necessary in the case of an asymptomatic fibroid. A possible future desire for pregnancy must be taken into account as well as the age of onset of the menopause

- Type of approach and surgical procedure: myomectomy was the dominant procedure, i.e. $75.65 \%$, exclusively by the abdominal route ( $100 \%)$, while hysterectomy was performed in $24.35 \%$ : abdominal route (laparotomy) $17.39 \%$ and vaginal route $6.96 \%$. Traoré D.V [2] in his series at the regional hospital of N'Zérékoré reported: $81.82 \%$ of myomectomies all performed by abdominal route, and $18.18 \%$ of hysterectomies of which: $13.13 \%$ were performed by abdominal route and $5.05 \%$ by vaginal route. Baldé I.S et al. [13] at the CHU of Conakry and Diallo M.H et al. [11] at the Ratoma CMC reported conservative surgical treatment in the majority of cases with $70 \%$ and $92.60 \%$ respectively.

The exclusivity of the abdominal approach can be explained by the fact that the fibroids were generally of large size.

\section{5-Pronosis}

-Duration of hospitalization: we found that $48.70 \%$ of patients were hospitalized between 3 and 5 days. The average length of stay was 6.05 days with extremes of 3 and 13 days. In the series by Traoré D.V. [2] at the regional hospital of N'Zérékoré, the hospital stay was 8.31 days. This relatively short stay in our series is due to the fact that the postoperative care was usually simple.

- Post-operative care: The post-operative care was simple in $75.65 \%$ and complicated in $24.35 \%$. Complications were dominated by anaemia in $13.04 \%$, of which the myomectomy was haemorrhagic and required a blood transfusion in $6.09 \%$. We also recorded $5.22 \%$ of parietal suppuration.

However, there were no cases of postoperative death. Diallo M.H. et al. [11] reported $34.82 \%$ of postoperative complications, represented mainly by anaemia with $23.70 \%$, resulting in a fatality rate of $1.48 \%$.

\section{Conclusion}

The frequency of the uterine fibromyomas is raised in the region of Labé and the hold in charge is often surgical.

\section{References}

1. Fernandez H., Azoulay C., Rostoker G., Ardaens K., Chevallier P., Cravello L. et al. (2005) Medical treatments for uterine fibroids, J Gynecol Obstet Biol Reprod 2005; 34: 360405.

2. Traore D.V. (2015) Uterine fibromyomas: epidemiological, clinical and therapeutic aspects at the regional hospital of N'Zérékoré, Thesis Med Guinea.Nº 0147.

3. Fanny M., Fomba M., Aka E., Adjoussou S., Olou L., Koffi A. et al. (2018) Prevention of haemorrhage by myomectomy in sub-Saharan Africa: contribution of the tourniquet on the uterine isthmus, Gynécologie Obstétrique Fertilité et Sénologie; 5

4. Traoré S.D. (2011)Epidemiological and therapeutic aspects of uterine fibroids at the Fousseyni Daou hospital in Kayes. Thesis Med Mali.

5. Fernandez H., Chabbert Buffet N., Allouche S. (2014) Prevalence of uterine fibroids in France and impact on quality of life from a survey of 2500 women aged 30-55 years, Journal of Obstetrics Gynecology and Reproductive Biology;p: 7

6. George A., Catherine A., Philippe-Yves L., Nicholas L. (2015)Management of uterine leiomyomas, J Obstet Gynaecol Can;37(2):179-181)

7. Fernandez H., Chabbert-Buffet N., Koskas M., Nazac (2014) A. Epidemiology of uterine fibroid in France in 20102012 in health care institutions - Analysis of data from the medicalised information systems programme (PMSI), Journal of Obstetrics Gynaecology and Reproductive Biology 43, 616628.

8. Coulibaly M.B, Traoré A., Camara M.A, Togo A., Sangaré A., Ongoiba I. et al. (2020) Gynecological etiologies of hysterectomies at the hospital in Mali about 70 cases, Jaccr Africa; 4 (1): 78-85. 
9. Dina H. (2020) Profil, impacts et prise en charge des fibromyomes utérins à propos de 173 cas, Thèse Med Maroc, $\mathrm{N}^{\circ} 210$.

10. Coulibaly A., Sima M., Traoré M.S, Kanté I., Dao S.Z, Koné K. et al. (2020) The place of uterine fibromyoma in patients who consult for infertility at the Obstetric Gynecology Department of the CHU Point G, Rev. Malian from Sci. and Technology; 1 (23): 1987-1031.

11. Diallo M.H, Baldé I.S, Diallo A.D, Baldé O., Diallo F.B, Fofana M.S et al. (2020) Surgical intervention on uterine fibromyoma in a country with limited resources: the case of the gynecology-obstetrics department of the Ratoma communal medical centre in Conakry-Guinea. Open Journal of Obstetrics and Gynecology ;10,05:11 p

12. Baldé I.S., Sy T., Diallo B.S., Diallo Y., Mamy M.N., Diallo M.H. et al. Les (2014)hystérectomies au CHU de Conakry : socio-demographic and clinical characteristics, types, indications, approaches and prognosis, Tropical Medicine and Health; 24: 379-382

13. Baldé I.S., Diallo B.S., Conté I., Baldé O., Diallo M.H., Diallo B.C et al. (2015) UTERINE FIBROMYOMAS:
Epidemiological, clinical, surgical management and prognosis aspects at Conakry University Hospital. Rev int sc med-RISM; 17.3: 118-124.

14. Onikoyamou F. Uterine fibroid: (2008) Clinical and therapeutic epidemiological aspects at Kamsar hospital. Thesis Med Guinea: 7 - 66.

15. [15] Rakotonirina H.A. Uterine fibroma: (2017) Epidemiological, clinical and therapeutic aspects in the Gynecology-Obstetrics Department of the BEFELATANANA University Hospital. Thesis Med Madagascar. $\mathrm{N}^{\circ}: 8972$

16. Magassouba D. Epidemio- (2008) clinical and therapeutic study of uterine fibroids in the Gynecology-Obstetrics service of the CHU du point G. Thesis Med Mali.

17. Fofana M.S S (2013) surgical intervention for uterine fibromyoma: Socio-demographic aspects, diagnosis and prognosis in the Obstetric Gynecology Department of the Ratoma Communal Medical Centre. Thesis Med Guinée. $\mathrm{N}^{\circ}$ : 451

18. Laghzaoui Boukaidi M., Bouhya S., Hermas S., Bennani O., Aderdour M. (2001) Epidemiology of uterine fibroids (about 690 cases). Maroc medical, 23: 266 - 270.
(ब) (1)

This work is licensed under Creative Commons Attribution 4.0 License

To Submit Your Article Click Here: Submit Manuscript

DOI: $10.31579 / 2578-8965 / 061$

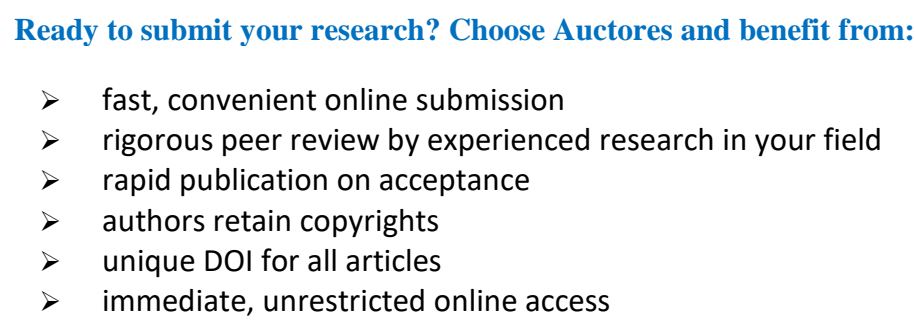

Ready to submit your research? Choose Auctores and benefit from:

$>$ fast, convenient online submission

$>$ rigorous peer review by experienced research in your field

$>$ rapid publication on acceptance

$>$ authors retain copyrights

$>$ unique DOI for all articles

$>$ immediate, unrestricted online access

At Auctores, research is always in progress.

Learn more auctoresonline.org/journals/obstetrics-gynecology-andreproductive-sciences 